\title{
Ozone therapy is an effective therapy in chronic fatigue syndrome: result of an Italian study in 65 patients
}

\author{
Umberto Tirelli, Cinzia Cirrito, Martina Pavanello \\ Tumor Center, Chronic Fatigue, Fibromyalgia and Oxygen Ozone Therapy, MEDE Clinic, Sacile (PN); Scientific Society \\ of Oxygen-Ozone Therapy (SIOOT), Gorle (BG), Italy
}

\begin{abstract}
The terms chronic fatigue syndrome and myalgic encephalomyelitis describe a complex physical illness characterized by debilitating fatigue, post-exertional malaise, pain, cognitive problems, sleep dysfunction and an array of other immune, neurological and autonomic symptoms. At the MEDE Clinic of Sacile, Italy, from February 2016 to December 2017, we have treated 65 patients, with auto hemo transfusion, according to the Scientific Society of Oxygen Ozone Therapy (SIOOT) protocols, twice a week for one month and twice a month as maintenance therapy. In conclusion, at our knowledge this is the largest study of patients with chronic fatigue syndrome treated with ozone therapy. Oxygen ozone therapy is an effective therapy in the treatment of chronic fatigue syndrome. However, more patients are needed and in particular a longer follow up is a necessary. In the meantime, ozone therapy seems a treatment that, also because without any side effect, is possible to be proposed to patients with chronic fatigue syndrome that are not obtaining sufficient results from available therapy.
\end{abstract}

\footnotetext{
Correspondence: Umberto Tirelli, MEDE Clinic, via San Michele 1, Sacile (PN), Italy.

Tel.: +39.0434.780986.

E-mail: utirelli@cro.it

Key words: Ozone therapy; Chronic fatigue syndrome.

Contributions: the authors contributed equally.

Conflict of interest: the authors declare no potential conflict of interest.

Funding: none.

Received for publication: 6 September 2018

Revision received: 10 September 2018.

Accepted for publication: 10 September 2018.

CC Copyright U. Tirelli et al., 2018

Licensee PAGEPress, Italy

Ozone Therapy 2018; 3:7812

doi:10.4081/ozone.2018.7812

This article is distributed under the terms of the Creative Commons Attribution Noncommercial License (by-nc 4.0) which permits any noncommercial use, distribution, and reproduction in any medium, provided the original author(s) and source are credited.
}

\section{Introduction}

The terms chronic fatigue syndrome and myalgic encephalomyelitis (ME/CFS) describe a complex physical illness characterized by debilitating fatigue, post-exertional malaise, pain, cognitive problems, sleep dysfunction and an array of other immune, neurological and autonomic symptoms. ${ }^{1-34}$ The key feature of the syndrome, post-exertional malaise, is the exacerbation of symptoms following minimal physical or mental activity, which can persist for hours, days or even weeks. Rest and sleep produce only modest relief of fatigue and the other symptoms. The illness is also characterized by substantially reduced physical and/or cognitive functioning.

Although ME/CFS is a physical illness, secondary psychological symptoms may be present as in many chronic conditions. ${ }^{35-42}$

The term myalgic encephalomyelitis (ME) was coined in 1956 to describe a well-documented cluster outbreak of a fatiguing illness in London, England. The name chronic fatigue syndrome (CFS) was proposed following the investigation of a cluster outbreak of a similar fatiguing illness in Nevada (USA) in 1984. CFS replaced the preliminary name, Chronic Epstein-Barr virus syndrome, because clinical studies were unable to confirm Epstein-Barr virus as the putative cause. The name chronic fatigue syndrome has been criticized as being vague and trivializing of the illness. CFS has also been confused with the common non-specific complaint of chronic fatigue. Other less common names for the illness are myalgic encephalopathy and chronic fatigue immune dysfunction syndrome. The World Health Organization classifies myalgic encephalomyelitis as a disease of the central nervous system (G93.3.). A similar illness, post-viral fatigue syndrome, describes the lingering of fatigue subsequent to a viral infection.

The name ME is more commonly used in Europe and Canada, while the CFS term is more often used in the USA and Australia. A number of different but overlapping case definitions have been published for each of the two terms. Most research studies use CFS because a specific case definition ${ }^{10}$ was written for this purpose. The acronyms ME/CFS and CFS/ME are increasingly being used worldwide.

The majority of patients present as sporadic or isolated 
cases, although cluster outbreaks of ME/CFS have occurred in many widely dispersed locations including: Iceland (1948), London, England (1955), New Zealand (1984), and the USA (Nevada, 1984; New York State and North Carolina, 1985). The illness affects all ages, races and socioeconomic groups. Onset usually occurs between the ages of 30 and 50 years, but may occur at almost any age. It has been estimated that $0.42 \%$ of the adult U.S. population have ME/CFS and $70 \%$ are female. Higher and lower prevalence estimates have been published for several countries outside the U.S. The prevalence in adolescents and children is uncertain, but appears to be lower than in adults, with equal numbers of boys and girls affected. With no validated diagnostic test for the illness, diagnosis is based on patientreported symptoms as described in several overlapping case definitions. This primer will use the 2003 Canadian Clinical Case definition, ${ }^{1-33}$ which is intended for clinical practice and better targets the key symptoms of ME/CFS. Although considerable media attention has been given to ME/CFS, most patients with the illness have not been diagnosed. Brain imaging studies with SPECT, PET and MRI have found abnormalities in both white and gray matter. Cognitive testing has confirmed problems that are independent of any coexisting psychological disorder. One group has reported a signature using EEG data that distinguishes patients with ME/CFS from patients with depression and from healthy subjects. Neuro-endocrine studies have identified abnormalities in several hypothalamic endocrine releasing hormone axes, abnormalities that often are the opposite of what is seen in major depression. Studies of spinal fluid proteins have found unique patterns, and spinal fluid concentrations of lactic acid (and, hence, $\mathrm{pH}$ ) are abnormal. Finally, many studies have identified abnormalities of the autonomic nervous system in patients with ME/CFS. Many (but not all) patients state that their illness began suddenly, with an infectious-like illness. There is good evidence that ME/CFS can follow in the wake of several different viral and bacterial infections. Indeed, it seems unlikely that a single novel infectious agent will prove to be a cause of the great majority of cases. Also, there is evidence that several viruses that produce latent, life-long infection in many humans may be reawakened or reactivated in $\mathrm{ME} / \mathrm{CFS}$, although it is unclear if this is the cause or the effect of the illness. Many studies have found evidence of chronic $\mathrm{T}$ cell activation. A recent study of the drug rituximab provides indirect evidence for chronic B cell activation, as well. Despite the substantial progress that has been made in understanding the underlying biology of ME/CFS, we still don't have a sufficiently accurate diagnostic test, or a proven treatment. Since last few decades, the therapeutic potential of ozone has gained much attention through its strong capacity to induce controlled and moderated oxidative stress when administered in precise therapeutic doses. A plethora of scientific evidence showed that the activation of hypoxia inducible factor- $1 \alpha$, nuclear factor of activated $\mathrm{T}$ cells, nuclear factor-erythroid 2-related factor 2-antioxidant response element, and activated protein-1 pathways are the main molecular mechanisms underlying the therapeutic effects of ozone therapy. Activation of these molecular pathways leads to up-regulation of endogenous antioxidant systems, activation of immune functions as well as suppression of inflammatory processes, which is important for correcting oxidative stress in chronic fatigue syndrome. ${ }^{43-63}$

\section{Materials and Methods}

At the MEDE Clinic of Sacile, Italy, from February 2016 to December 2017, we have treated 65 patients, with auto hemo transfusion (GAE), according to the Scientific Society of Oxygen Ozone Therapy (SIOOT) protocols, twice a week for one month and twice a month as maintenance therapy. Females were 50, males were 15; age ranged from 13 to 60 years and the time from CFS diagnosis ranged from 1 to 15 years. To assess the extent of fatigue we used the Fatigue Severity Scale which is used to estimate the severity of the symptom with a score ranging from 1 to $7.35-42$

\section{Results}

Of the 65 patients with CFS we have treated, 52 patients (80\%) showed a significant improvement in symptomatology ( $>50 \%$ improvement in symptoms). There have been no side effects to ozone therapy.

\section{Discussion and Conclusions}

Standardized medical care (antidepressants, glucocorticoids, immunotherapy and metabolic drugs) is scarcely beneficial and with some side effects in CFS patients. During the last seven years of clinical experimentation in vasculopathic and in age-related macular degeneration patients, we consistently noted that ozonate autohemotherapy often yields a feeling of wellbeing and euphoria. This result is interesting, and we can only speculate that the reasons for these positive effects are due to a functional restoration of hormonal and neurotransmitter functions. Why not than try the therapeutic shock of ozone autohemotherapy in patients plagued by fatigue and depression? Moreover, ozone therapy may change the vicious circle due to a chronic oxidative stress and deranged muscle metabolism. The clinical results so far obtained appear to justify the use of ozone in this frustrating pathology. It is worth noting that ozone therapy is effective because it is able to activate simultaneously several metabolic pathways that have gone astray. Eighty percent response rate obtained in our patients means that the ozone therapy is an effective therapy in chronic fatigue syndrome.

In conclusion, at our knowledge this is the largest study of patients with CFS treated with ozone therapy. Oxygen ozone therapy is an effective therapy in the treatment of chronic fatigue syndrome. However, more patients are need- 
ed and in particular a longer follow up is a necessary. In the meantime, ozone therapy seems a treatment that, also because without any side effect, is possible to be proposed to patients with chronic fatigue syndrome that are not obtaining sufficient results from available therapy.

\section{References}

1. The International Association for Chronic Fatigue Syndrome/Myalgic Encephalomyelitis (IACFS/ME). ME/CFS: a primer for clinical practitioners. Available from: www.iacfsme.org

2. Tirelli U, Age.Na.S. Chronic Fatigue Syndrome, CFS; 2014. Available from: www.umbertotirelli.it/140314CFSQUOTIDIANO\%20SANITA.pdf

3. Arpino C, Carrieri MP, Valesini G, et al. Idiopathic chronic fatigue and chronic fatigue syndrome: a comparison of two case-definitions. Ann Ist Super Sanità 1999;35:435-41.

4. Bennett RM, Smythe HA, Wolfe F. Recognizing fibromyalgia. Patient Care 1989;23:60-83.

5. Campbell SM, Clark S, Tindall EA, et al. Clinical characteristics of fibrositis. I. A "blinded," controlled study of symptoms and tender points. Arthritis Rheum 1983;26:817-24.

6. Canadian Expert Consensus Panel Clinical Case Definition for ME/CFS. J Chronic Fatigue Syndr 2003;11:7-116.

7. Cannon JG, Angel JB, Abad LW, et al. Interleukin-1beta, interleukin-1 receptor anatagonist, and soluble interleukin-1 receptor type II secretion in chronic fatigue syndrome. J Clin Immunol 1997; 17:253-61.

8. Carruthers BM, van de Sande MI, De Meirleir KL, et al. Myalgic encephalomyelitis: International Consensus Criteria. J Intern Med 2011;270:327-38.

9. Conti F, Priori R, De Petrillo G, et al. Prevalence of chronic fatigue syndrome in Italian patients with persistent fatigue. Ann Ital Med Int 1994;9:219-22.

10. Fukuda K, Straus SE, Hickie I, et al. The chronic fatigue syndrome: a comprehensive approach to its definition and study. International Chronic Fatigue Syndrome Study Group. Ann Intern Med 1994;15:953-9.

11. Giacalone A, Berretta M, Spina M, Tirelli U. Is long-term fatigue in patients with cancer an infrequent symptom? J Clin Oncol 2012;30:4175.

12. Giacalone A, Quitadamo D, Zanet E, et al. Cancer-related fatigue in the elderly. Support Care Cancer 2013;21:2899-911.

13. Giacalone A, Spina M, Berretta M, Tirelli U. Two types of fatigue in cancer patients. Br J Cancer 2012;106:424.

14. Häuser W, Akritidou I, Felde E, et al. Steps towards a symptom-based diagnosis of fibromyalgia syndrome. Symptom profiles of patients from different clinical settings. $Z$ Rheumatol 2008;67:511-5.

15. Holmes GP, Kaplan JE, Gantz NM, et al. Chronic fatigue syndrome: a working case definition. Ann Intern Med 1988;108:387-9.

16. Jain KA, Carruthers M, Van De Sande MI, et al. Fibromyalgia Syndrome: Canadian clinical working Case Definition, diagnostic and treatment protocols - A consensus document. J Musculoskeletal Pain 2003;4:3-107.

17. Kroenke K, Wood DR, Mangelsdorff AD, et al. Chronic fatigue in primary care. Prevalence, patient characteristics, and outcome. JAMA 1988;206:929-34.

18. Kruesi MJP, Dale J, Straus SE. Psychiatric diagnoses in patients who have chronic fatigue syndrome. J Clin Psychiatry 1989;50:53-6.

19. Kuczmarski RJ. Prevalence of overweight and weight gain in the United States. Am J ClinNutr 1992;55:495-502.

20. Lessard JA, Russell IJ. Fibrositis/fibromyalgia in private rheumatology practice; systematic analysis of a patient data base. In: Hyde BM, Goldstein J, Levine P, eds. The Clinical and Scientific Basis of Myalgia Encephalomyelitis/Chronic Fatigue Syndrome. Ottawa, Canada: The Nightingale Research Foundation; 1992.

21. Manu P, Lane TJ, Matthews DA. Somatization disorder in patients with chronic fatigue. Psychosomatics 1989;30:388-95.

22. Manu P, Matthews DA, Lane TJ. Panic disorder among patients with chronic fatigue. South Med J 1991;84:451-6.

23. Spazzapan S, Bearz A, Tirelli U. Fatigue in cancer patients receiving chemotherapy: an analysis of published studies. Ann Oncol 2004;15:1576.

24. Swartz MN. The chronic fatigue syndrome-one entity or many? N Engl J Med 1988;319:1726-8.

25. Tavio M, Milan I, Tirelli U. [Tumor-correlated asthenia]. Recenti Prog Med 2002;93:610-6.

26. Tavio M, Milan I, Tirelli U. Cancer-related fatigue (review). Int J Oncol 2002;21:1093-9.

27. Tavio M, Tirelli U. Astenia correlata ai tumori. In: Bonadonna G, Robustelli della Cuna G, Valagussa P, eds. Medicina Oncologica, 7th ed. Milan, IT: Elsevier; 2003.

28. Tirelli U, Chierichetti F, Tavio M, et al. Brain positron emission tomography (PET) in chronic fatigue syndrome: preliminary data. Am J Med 1998;105:54S-8S.

29. Tirelli U. La stanchezza quando diventa una malattia: La sindrome da fatica cronica (CFS). Ravenna, IT: SBC Edizioni; 2014.

30. Walker EA, Katon WJ, Jemelka RP. Psychiatric disorders and medical care utilization among people in the general population who report fatigue. J Gen Intern Med 1993;8:436-40.

31. Wessely S, Nimnuan C, Sharpe M. Functional somatic syndromes: one or many? Lancet 1999;354:936-9.

32. Wessely S, Powell R. Fatigue syndromes: a comparison of chronic post-viral fatigue with neuromuscular and affective disorders. J Neurol Neurosurg Psychiatry 1989;42:940-8.

33. White KP, Speechley M, Harth M, Ostbye T. Coexistence of chronic fatigue syndrome with fibromyalgia syndrome in the general population - a controlled study. Scand J Rheumatol 2000;29:44-51.

34. Annunziata MA, Muzzatti B, Mella S, et al. The recise piper fatigue scale (PFS-R) for Italian cancer patients: a validation study. Tumori 2010;96:276-81.

35. Bergman S. Psychosocial aspects of chronic widespread pain and fibromyalgia. DisabilRehabil 2005;27:675-83.

36. Giacalone A, Polesel J, De Paoli A, et al. Assessing cancerrelated fatigue: the psychometric properties of the Revised Piper Fatigue Scale in Italian cancer inpatients. Support Care Cancer 2010;18:1191-7.

37. Leavitt F, Katz RS, Golden HE, et al. Comparison of pain properties in fibromyalgia patients and rheumatoid arthritis patients. Arthritis Rheum 1986;29:775-81.

38. Masuda A, Nozoe SI, Matsuyama T, Tanaka H. Psycho behavioral and immunological characteristics of adult people with chronic fatigue and patients with chronic fatigue syndrome. Psychosom Med 1994;56:512-8.

39. Wolfe F, Clauw DJ, Fitzcharles MA, et al. Preliminary Diagnostic Criteria for Fibromyalgia and Measurement of Symptom Severity. Arthritis Care Res 2010;62:600-10.

40. Wolfe F, Hawley DJ. Measurement of the quality of life in 
rheumatic disorders using the EuroHRQoL. Br J Rheumatol 1997;36:786-93.

41. Wolfe F, Smythe HA, Yunus MB, et al. The American College of Rheumatology Criteria for the Classification of Fibromyalgia. Report of the Multicenter Criteria Committee. Arthritis Rheum 1990;33:160-72.

42. Arnett SV, Alleva LM, Korossy-Horwood R, Clark IA. Chronic fatigue syndrome - A neuroimmunological model. MedHyp 2011;77:77-83.

43. Bansal AS, Bradley AS, Bishop KN. Chronic fatigue syndrome, the immune system and viral infection. Brain Behav Immun 2011;26:24-31.

44. Barker E, Fujimura SF, Fadem MB, et al. Immunologic abnormalities associated with chronic fatigue syndrome. Clin Infect Dis 1994;18:S316-41.

45. Broderick G, Fuite J, Kreitz A, et al. A formal analysis of cytokine networks in chronic fatigue syndromes. Brain Behav Immun 2010;24:1209-17.

46. Caligiuri M, Murray C, Buchwald D, et al. Phenotypic and functional deficiency of natural killer cells in patients with chronic fatigue syndrome. J Immunol 1987;139:3306-13.

47. Carlo-Stella N, Badulli C, De Silvestri A, et al. A first study of cytokine genomic polymorphisms in CFS: positive association of TNF-857 and IFN $\gamma 874$ rare alleles. Clin Exp Rheumathol 2006;24:179-82.

48. Fletcher MA, Zeng XR, Barnes Z, et al. Plasma cytokine in women with chronic fatigue syndrome. J Transl Med 2009;7:96.

49. Glaser R, Padgett DA, Litsky ML, et al. Stress-associated changes in the steady-state expression of latent Epstein-Barr virus: implications for chronic fatigue syndrome and cancer. Brain Behav Immun 2005; 19:91-103.

50. Hudson JI, Pope HG Jr. Affective spectrum disorder: does antidepressant response identify a family of disorders with a common pathophysiology? Am J Psychiatry 1990;147:552-64.

51. Konstantinov K, von Mikecz A, Buchwald JJ, et al. Autoantibodies to nuclear envelope antigens in chronic fatigue syndrome. J Clin Invest 1996;98:1888-96.

52. Landay AL, Jessop C, Lennette ET, Levy JA. Chronic fatigue syndrome: clinical condition associated with immune activation. Lancet 1991;338:707-12.

53. Lerner AM, Beqai SH, Deeter RG, Fitzgerald JT. Valacyclovir treatment in Epstein-Barr virus are subset chronic fatigue syndrome: thirty-six months follow-up. In Vivo 2007;21:707-13.

54. Moss RB, Mercandetti A, Vojdani A. TNF-alpha and chronic fatigue syndrome. J Clin Immunol 1999;19:314-6.

55. Natelson BH, Haghighi MH. Evidence for the presence of immune dysfunction in chronic fatigue syndrome. Clin Diagn Lab Immunol 2002;9:747-52.

56. Nishikai M. Antinuclear antibodies in patients with chronic fatigue syndrome. Nippon Rinsho 2007;265:1067-70.

57. Pellegrino MJ. Atypical chest pain as an initial presentation of primary fibromyalgia. Arch Phys Med Rehabil 1990;71:526-8.

58. Rohleder N, Schommer NC, Hellhammer DH, et al. Sex differences in glucocorticoid sensitivity of proinflammatory cytokine production after psychosocial stress. Psychosom Med 2001;63:966-72.

59. Rohleder N, Wolf JM, Piel M. Impact of oral contraceptive use on glucocorticoid sensitivity of proinflmmatory cytokine production after psychosocial stress. Psychoneuroendocrinology 2003;28:261-73.

60. terWolbeek M, van Doornern LJ, Kavelaars A, et al. Longitudinal analysis of pro- and anti-inflammatory cytokine production in severity fatigue adolescents. Brain, BehavImmun 2007;21:1063-74.

61. Tirelli U, Lleshi A, Berretta M, et al. Treatment of 741 Italian patients with chronic fatigue syndrome. Eur Rev Med Pharmacol Sci 2013;17:2847-52.

62. Tirelli U, Marotta G, Improta S, Pinto A. Immunological abnormalities in patients with chronic fatigue syndrome. Scand J Immunol 1994;40:601-8.

63. Tirelli U, Pinto A, Marotta G, et al. Clinical and Immunologic Study of 205 patients with chronic fatigue syndrome: A case series from Italy. Arch Intern Med 2003;153:116-20. 